\title{
ORGANIZACIÓN ADMINISTRATIVA PARA LAS ESTRUCTURAS URBANAS COMPLEJAS EN COLOMBIA
}

\author{
Jaime Enrique Rodríguez Navas \\ Magister en Derecho Público, Convenio Universidad Santo Tomás - Universidad de Konstanz-Alemania; \\ Especialista en Derecho Administrativo, Universidad Santo Tomás, Seccional Bucaramanga (Col); \\ Especialista en Derecho Minero y Energético, Universidad Externado de Colombia (Col); Especialista \\ en Derecho Público, Convenio Universidad Externado de Colombia - Universidad Autónoma de \\ Bucaramanga UNAB. Docente Universidad Santo Tomás - Seccional Bucaramanga (Col). \\ E-mail: jaimeenriquerodrigueznavas@yahoo.es
}

\begin{abstract}
Resumen
El presente trabajo se propone describir y analizar críticamente la normativa adoptada en Colombia para facilitar la administración de las estructuras urbanas complejas características de las sociedades industriales y postindustriales. Deliberadamente se prescinde del estudio de las organizaciones infra municipales, útiles también para la mejor administración de las estructuras urbanas complejas, para centrar la atención en la institucionalización de las redes de relación supramunicipal y particular y finalmente, en las áreas metropolitanas, por cuanto constituyen, si no el único, sí el más importante aporte a su administración. Inicia con un bosquejo semántico para homogeneizar, en cuanto sea posible, un lenguaje de referencia, mientras en forma simultánea y somera recorre el íter del desarrollo del urbanismo en Colombia hasta los complejos conglomerados de finales de siglo XX, continúa con la descripción y el análisis crítico de la institucionalidad vigente, y cierra con el trazo de algunos basamentos para una agenda legislativa de reforma al régimen orgánico administrativo en la materia.
\end{abstract}

\section{Palabras clave}

Estructuras urbanas complejas, metrópoli, área metropolitana, aglomeración urbana, cabecera municipal, conurbación, ciudad, institucionalización, metropolización, urbanismo, administración, organización administrativa.

\begin{abstract}
The present paper proposes to describe and critically analyze the adopted regulation in Colombia that allows the administration of complex urban structures typical of industrial and post-industrial societies. Deliberately, it was ignored the study of infra municipal organizations, useful as well for a better management of complex urban structures, to focus the attention on institutionalized networks of supra-municipal relationship and particular and finally, the metropolitan areas, by which they constitute, if not the only, it is the most important contribution to its administration. It starts with a semantic sketch to homogenize, as much as possible, common terms of reference, while simultaneously and in light manner, go through the iter of the development of urbanism in Colombia from the complex conglomerates from the late twentieth century, continuing the description and critical analysis of the current institutionalism, and closes with the outline of some bases for a legislative agenda to reform the administrative regime on the matter.
\end{abstract}

\section{Key Words}

Complex urban structures, metropolis, metropolitan area, urban area, municipal, metropolitan area, city, institutionalization, metropolis, urban planning, management, administrative organization. 

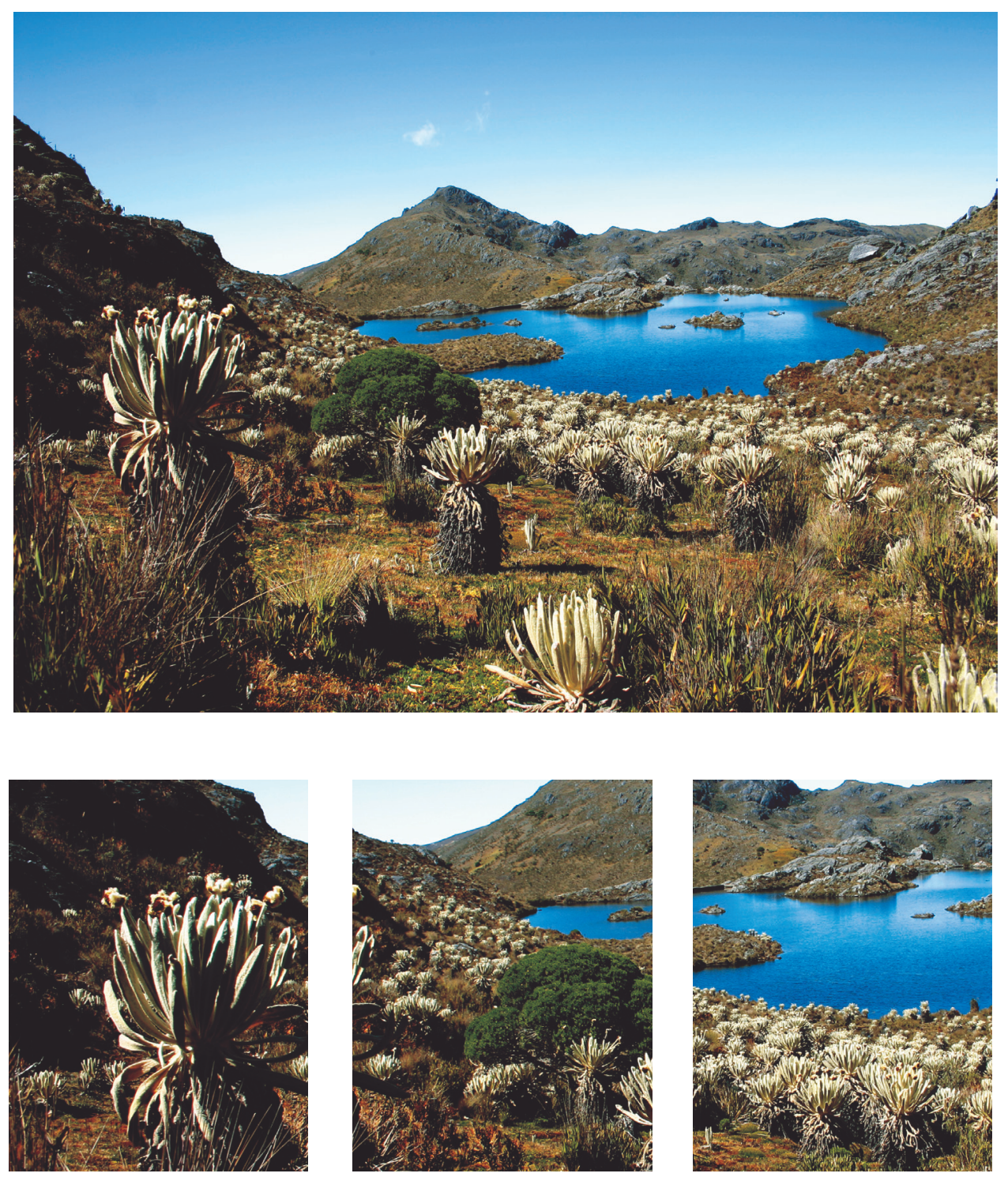

Laguna Oriental 


\section{ORGANIZACIÓN ADMINISTRATIVA PARA LAS ESTRUCTURAS URBANAS COMPLEJAS EN COLOMBIA*}

Jaime Enrique Rodríguez Navas

\section{Introducción}

La dinámica observada por los centros urbanos en Colombia a lo largo del siglo $\mathrm{XX}$, respondió, sin perjuicio de algunas particularidades y vicisitudes, a una tendencia universal caracterizada por la aparición de formas cada vez más complejas de estructuración y funcionamiento de su espacio físico, por la simultánea y creciente densificación de las concentraciones de población y por la complicación de las relaciones de diverso orden entre poblaciones circunvecinas.

Esta tendencia general ha estado determinada por factores intrínsecos en las colectividades municipales históricas, como las altas tasas de natalidad que presentaron las urbes hasta mediados de la pasada centuria y la elongación que ha experimentado la expectativa de vida por el avance de la medicina y el mejoramiento de las condiciones generales de higiene y saneamiento básico; pero también, por factores de diversa índole, como los desastres naturales, los cambios climáticos y la distribución asimétrica entre las diferentes poblaciones de las oportunidades de desarrollo económico y de bienestar que se derivan de los procesos de industrialización de los centros urbanos y de sus entornos (Naredo, 2000).

\footnotetext{
* El presente artículo es producto del proyecto de investigación: Ingobernabilidad de las Áreas Metropolitanas: Un problema de etiología normativa, adelantado por el Grupo de Investigación de Derecho Público USTABGA en desarrollo de la Línea de Investigación: Gobierno y Administración del Estado Social de Derecho.
} 
Latinoamérica toda, acusó las consecuencias de esta dinámica, con la hipertrofia de las ciudades capitales y el correlativo despoblamiento de otros centros urbanos históricos, circunstancia que generó una respuesta del ordenamiento jurídico en el sentido de dotar a las capitales de un régimen jurídico especial y único. Sólo a partir de los años 60 y 90, esta tendencia se modificó, para dar lugar al ascenso de otros centros urbanos cuyo crecimiento les permitió entrar a competir con las capitales como centros receptores de migración interna. Tal fue el caso de Sao Pablo, Río de Janeiro, Belo Horizonte, Porto Alegre, Curitiba, Salvador, Fortaleza y Brasilia, en Brasil; Rosario y Córdoba en Argentina; Guadalajara, Monterrey, Puebla, Toluca, Irapuato, Ciudad Juárez y León en México; o Maracaibo y Valencia en Venezuela (Varela, 1998).

Colombia observó una dinámica un tanto diferente, pues desde el siglo XIX presentó un relativo equilibrio en la concentración significativa de población entre la capital y por lo menos otras tres ciudades: Medellín, Cali y Barranquilla (Safford y Palacios, 2005), equilibrio que permitió predicar, por lo menos hasta los años treinta, que cualquiera de estas ciudades, por su importancia, por su significación industrial, comercial o portuaria, así como por el volumen y densidad de su población, bien hubiera podido obrar como capital del país.

Hacia los años setenta las grandes concentraciones urbanas resultantes del nuevo modelo de planeación fundado de manera principal en el impulso de la actividad constructora (Uniandes, 2006), así como de las migraciones internas provocadas por la violencia política partidista (Ruiz, 2008) e insurgente se multiplicaron en torno a, por lo menos, cinco centros de conurbación aparte del Distrito especial de Bogotá, y hoy, tras la arremetida de la lucha contrainsurgente (Khoudour-Casteras, 2009) y los desequilibrios regionales que provocó la economía urbana subterránea del narcotráfico, catapultaron un número cercano a quince (15) ciudades intermedias cuyas características permiten que se les califique como núcleos de procesos de aglomeración poblacional.

Esta particular situación, si bien se vio impulsada indirectamente por el plan de desarrollo denominado: de las cuatro estrategias (Moncayo, 2002), no alcanza a explicarse suficientemente como una consecuencia de la iniciativa estatal, pues la temática regional y local ocupó un lugar marginal en el marco político institucional, como colofón del viejo edificio centralizador de la constitución de 1886, y el consiguiente desequilibrio fiscal que convirtió a la administración nacional en "el principal recaudador de impuestos y proveedor de bienes y servicios públicos", sumado a la tendencia napoleónica del ordenamiento a regular con una misma normativa a los municipios sin reparar en las diferencias existentes entre ellos (OCAMPO, 1984), dejó el crecimiento de los centros urbanos al impulso de vientos coyunturales que mejor consultaban los intereses del empresariado urbanizador legal o subterráneo, que el interés general cuya orientación se presumía monopolizada por el Estado. 
Sin embargo, el crecimiento que experimentaron entre los años 60 y 70, en especial, las ciudades de Medellín, Cali, Barranquilla, Bucaramanga, Pereira y Cúcuta, tendió entre cada una de ellas y las ciudades circunvecinas una compleja red de relaciones y problemas cuya atención, no sólo trascendía los preciosos linderos de sus jurisdicciones, sino que escapaba a las capacidades de gestión de las arcaicas administraciones municipales.

Resultaba preciso crear o autorizar nuevas formas de organización institucional para responder adecuadamente a esta nueva realidad crecientemente compleja por causa, tanto de la densificación poblacional, constructiva y relacional, en general, característica de la vida urbana, como de las demandas de nuevos servicios que la higiene, la salubridad pública y las comunicaciones, en especial, reclamaban en estas aglomeraciones interrelacionadas.

Este proceso de institucionalización se ha llevado a efecto en dos periodos diferenciados. El primero, se inició en la reforma constitucional de 1968 y se extiende hasta la entrada en vigencia de la Constitución de 1991. El segundo, cuenta desde este hito, hasta hoy.

El objeto de este trabajo es el análisis de pertinencia, oportunidad y coherencia de la normativa que desde 1968 ha enriquecido a nuestro ordenamiento jurídico con ese propósito en términos que permitan delinear una especie de hoja de ruta para su optimización. Inicia con un bosquejo semántico para homogeneizar, en cuanto sea posible, un lenguaje de referencia, al tiempo que recorre, someramente, el iter del desarrollo del urbanismo en Colombia hasta los complejos conglomerados de finales de siglo XX; continúa con la descripción y el análisis crítico de la institucionalidad vigente; y cierra con el trazo de algunos lineamientos de la agenda que debería recorrerse para ajustarla a los requerimientos de una buena administración.

La pertinencia del tema salta a la vista con decir que la estadística oficial revela una concentración del cuarenta por ciento $(40 \%)$ de la población nacional en las áreas metropolitanas funcionales del país, (DANE, 2005); que más del cincuenta por ciento $(50 \%)$ de la migración interna tiene como destino las capitales de departamento y las áreas metropolitanas (Pérez, 2003), y que esta concentración encuentra su correlato en el ámbito de las estadísticas de empleo y producción (Iregui, Melo y Ramírez, 2006), circunstancia que obliga a pensar en las áreas metropolitanas como centros ideales de relación con una economía de signo global.

Sin una administración pertinente que promueva la planificación integral, lidere el desarrollo metropolitano allende los estrechos confines parroquiales, construya ciudadanía, y articule ventajas competitivas, esta visión resulta ser tan sólo una quimera. 


\section{Aproximación semántica a la complejidad urbana contemporánea. Una perspectiva a partir del ordenamiento jurídico}

A despecho de la inutilidad que desde el punto de la geografía urbana se predica de la distinción radical entre los espacios y las formas de vida urbana y rural en la contemporaneidad (Capel, 1975), parece razonable admitir que cualquier esfuerzo de precisión semántica para la construcción de una legislación administrativa local, debe partir de una aproximación, cuando menos, al sentido y alcance de estos dos términos.

Varios son los criterios que se emplean para deslindar uno y otro concepto, y diferentes las tendencias que se forman, por razón del énfasis que se da a cada uno de estos.

Entre los criterios de más usual aplicación, se encuentra la diferenciación que reciben los usos del suelo, las actividades económicas y los modos de vida preponderantes entre los habitantes de fracciones del territorio local, el grado de densidad de la población en función del territorio, y la oferta de servicios y equipamientos, entre otros no menos importantes, pero cuya relevancia práctica dependerá de cada cultura y del grado de desarrollo económico de cada contexto geo-sociológico (Precedo Ledo 1988 p. 14).

Al margen del debate teórico que sobre el tema continúa abierto, en el caso colombiano, un examen de la normativa jurídica vigente en materia de organización administrativa municipal hasta los albores de los años sesenta de la pasada centuria, aún incardinada por la ley 4 de 1913, pone de presente que el legislador centraba su atención sobre el contexto integral del municipio, diferenciaba, cuando encontraba motivo para ello, entre la cabecera municipal y el resto de su territorio. Así, por ejemplo, los límites del poder de policía para la ordenación territorial de los mercados, la localización de las instalaciones de la alcaldía, la forma de dar publicidad a las decisiones administrativas, se definían en la ley con referencia a la cabecera municipal.

Respondía esa legislación al bucólico orden de una vida municipal decimonónica que sólo justificaba la existencia de algún grado especial de concentración humana en torno al centro político administrativo y al marco de la plaza en la que preferentemente los días feriados, se reunía la oferta y la demanda de bienes y servicios.

A espaldas de ese orden, la industrialización, que había recibido un decisivo impulso durante el gobierno de Reyes, había transformado la vida en los principales núcleos regionales andinos y caribeños del país. El crecimiento y la consolidación de la industria textil, la progresiva penetración de generación y distribución de energía eléctrica, el desarrollo de la industria cervecera y de la producción industrial de bebidas gaseosas y el inicio de la actividad de exploración y explotación petrolífera, entre otras actividades, habían cambiado la fisonomía agrícola y artesanal de la sociedad colombiana para dar forma al empresariado industrial y al proletariado e 
impulsar el ejercicio de las profesiones liberales y del comercio, todo esto, en contextos que enriquecían las relaciones que se desarrollaban en las cabeceras municipales.

Fue así como, desde la segunda década del siglo XX, la legislación introdujo modificaciones en el quehacer de las autoridades municipales sin alterar, eso sí, su forma de organización, para responder a las preocupaciones propias de las corrientes urbanísticas europeas y norteamericanas que gravitaban, primero, en torno a las demandas de higienización de los nuevo núcleos de vida urbana ${ }^{1}$, y después, alrededor de la preservación de la estética ${ }^{2}$ en el diseño de la ciudad (Maldonado, 1999), aludía primero, en forma oblicua, y definía después, explícitamente el espacio y la vida urbana.

Es así como la ley 88 de 1947, al tiempo que conminaba a los concejos municipales a señalar el área urbana de sus poblaciones con determinación de la nomenclatura de las calles y carreras necesarias para dar cauce a la movilidad, definió dichas áreas, para los efectos del fomento y el desarrollo urbano, como

"la extensión comprendida dentro de la nomenclatura legal correspondiente o la determinada por los concejos municipales por medio de acuerdos".

En forma paralela, la estadística oficial empleaba la expresión áreas urbanas, para efectos del empadronamiento, como las superficies ocupadas por ciudades, cabeceras municipales, cabeceras de corregimientos, de inspecciones de policía, y caserios sin autoridad, con edificaciones agrupadas; y caracterizaba a las áreas rurales como superficies ocupadas por fincas agricolas, ganaderas o por regiones inexplotadas o improductivas, en las que las casas de habitación no constituyan agrupaciones (Martínez, 2001).

En resumen, una superposición de la incipiente legislación urbanística y los manuales de empadronamiento empleados por el DANE en el censo de 1964, permiten establecer la preponderancia que hasta los años setenta tuvieron, como factores delimitadores de lo urbano frente a lo rural, la localización de las edificaciones y espacios de gobierno y mercadeo, la densificación constructiva, la especialización industrial, comercial y de servicios de los usos del suelo, el diseño cuadricular del entramado vial y la delimitación administrativa general.

Así, lo urbano podría caracterizarse como un espacio socio-geográfico ocupado por familias que habitan construcciones edificadas en forma continua o cuando menos altamente próximas unas a otras y entre estas y los núcleos de equipamiento y servicio público, y organizadas en función de una compleja malla vial, en el que el uso del suelo se encuentra vinculado preponderantemente al desarrollo de las actividades comerciales, industriales y de servicios en las que centran su atención sus habitantes.

$1 \quad$ Cfr. leyes 46 de 1918 y 61 de 1936.

2 Cfr. Leyes 1 de 1943 y 88 de 1947. 
Por su parte, lo rural diría, entonces, relación con espacios socio-geográficos en los que sus habitantes ocupan el suelo y dedican su capacidad productiva en actividades preponderantemente agropecuarias, habitan construcciones edificadas con gran distancia las unas de las otras, y reciben un bajo nivel de beneficios derivados del equipamiento y el servicio público.

El surgimiento del tejido urbano como una estructura de complejidad organizada (Gehl, 1987) vino sucedido en Colombia, como en Europa y Estados Unidos, por la dinámica expansionista de sus contornos, con invasión del espacio rural y transformación de su paisaje en urbano. Esta dinámica, que se concentró sobre la capital y casi una decena de conglomerados humanos de intermedia importancia, se explica, a su vez, por diversos factores, entre los que cuentan las tasas crecientes de natalidad que se dieron hasta mediados del siglo $\mathrm{XX}$, el decrecimiento de la mortalidad por el progreso de la medicina y la actividad higienizadora del espacio urbano promovido por la legislación urbanística, y el movimiento inmigratorio provocado hacia esos conglomerados por corrientes sucesivas de campesinos y de habitantes de pequeños municipios que buscaban participación en los beneficios del desarrollo que allí anidaba, o huían de la miseria del agro y de persecución violenta de sus contradictores políticos o ideológicos (Ruiz, 2008).

El crecimiento asimétrico de algunos conglomerados cimentó progresivamente el uso de la expresión ciudad para aludir a las cabeceras municipales o núcleos urbanos que superaban un número considerablemente alto de habitantes, albergaban la sede de las más altas instancias administrativas, ofrecían los más elevados índices de cobertura en la prestación de servicios especializados y concentraban una sólida y fuerte actividad económica preponderantemente industrial y comercial con repercusiones nacionales o cuando menos regionales.

Esta expresión viene a ser empleada con alguna asiduidad por la legislación urbanística a partir de la ley 61 de 1978 para aludir a contextos urbanos con determinadas características que demandaban mayores exigencias en materia de planeación. Ese alcance, en relación con núcleos urbanos con más de 20.000 habitantes, se repite en el decreto ley 1333 de 1986 (art. 33), y se replantea e en la ley 9 de 1989 y en la ley 388 de 1997 para referir a los núcleos urbanos de municipios con población superior a los cien mil (100.000) habitantes como obligados a formular planes de desarrollo y planes de ordenamiento territorial y no planes de desarrollo simplificado y planes básicos de ordenamiento territorial.

La expansión física de las ciudades y la simultánea reducción, por obra de los medios de comunicación, de las distancias que las separaban, generó con el tiempo un entramado cotidiano de relaciones entre habitantes de distintas ciudades circunvecinas, de variada característica e intensidad.

De ordinario, dicho entramado surge como secuela del crecimiento de la influencia de una ciudad que obra como nodo del desarrollo regional, que causa impacto en la vida económica, social y cultural de ciudades y poblados circunvecinos de menor significación que conservan, sin embargo, su propia identidad. Otras veces, 
el acrecimiento de la ciudad nodo trasciende la esfera de la simple influencia y se proyecta físicamente hasta los contornos de ciudades, poblaciones o localidades satélites vecinas y desdibuja linderos cuya exactitud se diluye sigilosamente en la memoria colectiva. También puede ocurrir que dicho entramado sea reflejo del simultáneo crecimiento de varias ciudades de similar connotación, con reparto de su funcionalidad social y económica, de modo que el trabajo, la vivienda, los centros educacionales, los centros dispensadores de servicios, los mercados de los que se proveen, tienen asientos diferentes dentro de una misma conglomeración de ciudades.

Ese tipo de

"urbanización sin freno que se difunde por el territorio de forma errática e incontrolada, perdió la noción de centro y de unidad en el trazado que era propia de las antiguas ciudades" (Geddes, 1915),

y que puede ser entendido, bien como proceso o bien como resultado, fue reconocido por Geddes bajo la común denominación de conurbación.

Sin embargo, para facilitar el curso de la tesis central que este trabajo desarrolla, la expresión conurbación se toma en un sentido más estricto, para referir, conforme a la etimología, tanto los procesos de expansión horizontal simultánea de dos o más núcleos urbanos que lleva a que éstos se integren, para dar origen a nueva territorialidad con dinámicas de interrelación social, cultural, económica, política y ecológica, como estos resultados de integración. Por su parte, con recurrente apelación a la etimología, se reservará la expresión metropolización para aludir al proceso de expansión de un núcleo urbano central o principal que provoca por mérito y fuerza propios, la integración de otros núcleos periféricos.

Indistintamente, conurbaciones y metropolizaciones forjaron en Colombia, con especial intensidad entre los años sesenta y ochenta del siglo XX, complejas estructuras interurbanas que obligaron al sistema a revisar la normativa de la organización local en términos y condiciones que hicieran posible la eficiente prestación de los servicios públicos, unas veces, porque así lo imponía la formación de nuevos espacios y nuevas comunidades supramunicipales, y otras, porque así lo aconsejaba la prudencia en función de la generación de economías de escala favorables a las finanzas públicas locales.

Tempranamente, el constituyente de 1968 delineó el camino que habría de seguir la ley para institucionalizar procesos de administración de estas redes a la manera de asociaciones de municipios y áreas metropolitanas, ampliaba un derrotero que ya había iniciado en 1945 con la institucionalización del Distrito Especial de Bogotá.

Más recientemente, como eco de las resultas de un fallido proyecto de reforma constitucional que cursó en la Asamblea Nacional Constituyente de $1991^{3}$, se han expresado aspiraciones por parte de algunos municipios núcleos de área metropolitana

3 Cfr. ponencia presentada por Héctor Pineda ante la Comisión Segunda de la Asamblea Nacional Constituyente. 
de hacer tránsito a la condición de distritos metropolitanos, expresión que hace referencia a los distritos que, conforme lo autoriza el artículo 319 de la Constitución y lo desarrolla el artículo 128 de la ley 128 de 1994, resultan de la conversión de las áreas metropolitanas en Distritos.

En estos días está de moda que las ciudades se autodenominen ciudades globales y se endilguen la condición de núcleos de una ciudad región, circunstancia que obliga a hacer, cuando menos una pequeña referencia a estos conceptos que aún no son de recibo por la legislación pero que forman parte de la semántica de los más recientes ejercicios de planeación del desarrollo local.

Para su cabal comprensión conviene traer la explicación del concepto de región urbana como referente de algunas estructuras complejas interurbanas resultantes del incremento, en número e impacto, de las relaciones que se tejen entre varios asentamientos urbanos dispersos por la mediación de espacios rurales que adquieren bajo su influencia características sociales y económicas preponderantemente urbanas que conforman integralmente un espacio unitario. (Martínez, 2001).

Esta región urbana, a su vez, cuando se concibe en términos de las relaciones que demanda un mundo globalizado, como uno de sus nodos socioeconómicos, que gira en derredor de un lugar central que funciona como una ciudad global la cual actúa como emisora y receptora de procesos de intercambio entre la región y el mundo, de modo que le permite lograr integralmente su propio desarrollo y contribuir a la sostenibilidad de la Nación y del Planeta se habla, entonces, de la ciudad región (Boisier, 1993).

A su vez, la expresión ciudad global inmersa en la de ciudad región, es un trasunto de las teorías de la ciudad mundial (Geddes, 1915), desarrolladas a partir del papel que desempeñan ciudades como Nueva York, Londres y Tokio, como centros financieros globales, asiento de las más importantes corporaciones transnacionales (Friedmann \& Wolff, 1982; Feagin \& Smith, 1989), unidades geográficas fundamentales de los Estados y nodos de organización del capitalismo mundial.

Una ciudad que no funge siquiera como centro de un nutrido intercambio entre la región de su influencia y el mercado global, no es una ciudad global, ni confiere a la región a la que pertenece y lidera la condición de ciudad región.

La inclusión de este nuevo concepto en los planes de desarrollo de varios municipios, en especial de los que ofician como municipios núcleo de áreas metropolitanas, revela una visión estratégica de mediano o largo plazo, cuya realización dependerá del acompañamiento que esa intención reciba de una adecuada planeación integral y proactiva del desarrollo de las áreas metropolitanas que se han formado bajo su influencia. 


\section{Distritos, Áreas Metropolitanas Institucionales y Asociaciones de Municipios, en la organización administrativa territorial}

Los más representativos debates a lo largo de la vida republicana colombiana, en relación con la administración de la vida pública en los diversos territorios que integran el país, se han centrado en torno a la autonomía que han de tener en la gestión de sus asuntos propios.

En el siglo XIX tal debate polarizó a sus gentes en derredor de las doctrinas del unitarismo de Estado y del Federalismo. En el siglo XX, adscrito ya el Estado colombiano en la fórmula del unitarismo, el debate gravitó entre los extremos de la centralización y la descentralización administrativa. Esta última se abrió paso en la modalidad institucional bajo el signo de la especialidad a partir de 1968, y sólo desde 1986 y más enfáticamente, desde 1991, tomó rumbo hacia la descentralización territorial.

La administración de las grandes urbes, de las redes urbanas y las conurbaciones que sobrevinieron en los albores de la segunda mitad del siglo XX se debatió, como ha ocurrido en el mundo entero (Lefèvre, 2005), entre la descentralización por servicios y la descentralización territorial, entre la creación institucional y la asociación.

El ordenamiento jurídico colombiano ofrece tres formas de organización propicias para la administración de grandes urbes, de grandes conglomerados urbanos, y de redes de ciudades: las asociaciones de municipios, los distritos y las áreas metropolitanas.

\section{De las asociaciones de municipios}

Las asociaciones de municipios, conocidas en otras legislaciones, como la española (Bermejo, 1998) y la venezolana (Brewer Carías, 2005), con el nombre de mancomunidades de municipios, pueden ser estudiadas desde la perspectiva de su fundamento dogmático constitucional, como expresión del derecho de asociación que se deriva para los entes municipales del principio de la autonomía que las rige, o desde el punto de vista teleológico funcional, en consideración a su utilidad instrumental, como herramientas de cooperación para la mejor administración conjunta de servicios a cargo de varias municipalidades. Para los efectos de este estudio interesan las dos perspectivas.

Nuestro ordenamiento jurídico da cuenta de ellas a partir de la reforma constitucional de 1968, circunstancia que resulta explicable en la medida en que el acto legislativo No 1 de ese año fue la puerta de entrada por la que irrumpió la descentralización administrativa en Colombia, cuando menos en su tipo funcional, basado en la integración del principio de la especialización con el principio de la autonomía y la extensión de la personalidad a órganos corporativos o institucionales distintos del Estado. 
Eran tiempos esquivos para la autonomía territorial pese a la expresa declaración que del principio de descentralización hacía la Constitución de 1886, circunstancia que incidió en la extraña inclusión, al lado de las típicas asociaciones voluntarias de municipios, de otras asociaciones del mismo género pero de creación unilateral por parte de las Asambleas Departamentales bajo la única condición de conveniencia en función de los requerimientos de eficiencia y economía en la gestión administrativa a cargo de cada uno de los municipios comprometidos.

Paradójicamente, la Constitución de 1991, una Constitución autonomista en relación con las entidades territoriales y municipalista por excelencia, no se ocupó explícitamente de ellas, como sí lo hacía la Constitución precedente en su artículo 198. Una sola alusión, casi al paso, se encontraba en el inciso 4 del artículo 356 de su texto original con ocasión del entonces denominado situado fiscal, para disponer que los servicios públicos podían ser prestados por los municipios en forma individual o asociada. Sin embargo, con la reforma que experimentó este artículo en el acto legislativo 1 de 1993, y con las sucesivas reformas que le sobrevinieron, desapareció dicha alusión.

Ello no significa que carezcan de fundamento en el actual ordenamiento constitucional, pues sus raíces encuentran tierra fértil en el nodo relacional del derecho de libre asociación y el principio de la autonomía de las entidades territoriales y en particular del municipio.

En tal entendimiento, ha de entenderse la derogación expresa que hizo la ley 136 de 1994 de las disposiciones del decreto 1333 de 1986 que autorizaban la creación de asociaciones de municipios mediante acto unilateral de autoridad central.

Ese marco constitucional, la normativa derivada que las regula en la ley 1 de 1975, el decreto ley 1333 de 1986, la ley 136 de 1994, y el espíritu corporativo que las inspira, permite caracterizarlas en los siguientes términos:

- Son entidades nacidas del acuerdo de voluntades de un número plural de municipios, de modo que no responden a la necesidad de institucionalizar una realidad sociológica unitaria, preexistente y diferente al interés común de estos sujetos calificados, de aunar recursos y esfuerzos para la prestación en común de uno o más servicios que en principio sólo a cada uno de ellos concierne prestar, y que al margen de los motivos de conveniencia que aconsejan la asociación, podrían prestar por su propia cuenta. Dicho acuerdo se suscribe por los Alcaldes, previa autorización de los respectivos Concejos Municipales.

- Como expresión que son de la autonomía individual de los municipios, compete a éstos acordar su propio régimen interno de administración y, cuando menos, su nombre, domicilio, objeto, patrimonio, organización, procedimientos para desatar controversias entre los asociados, y su duración.

- Sin perjuicio de lo anterior, en sus relaciones jurídicas intersubjetivas o externas, se gobiernan por el derecho público considerada la naturaleza 
típicamente administrativa de las actividades constitutivas de su objeto, circunstancia que ha movido al legislador a transferirles, para el desarrollo del mismo, idénticas prerrogativas, privilegios y exenciones a los previstos en la ley a favor de los municipios a quienes concierne originariamente su ejecución.

- Significa lo anterior, que en la creación de la asociación opera una modalidad de descentralización indirecta, en virtud de la cual, se le transfieren a ésta competencias municipales específicas que las entidades territoriales asociadas no podrán ejecutar individual y separadamente mientras subsista la asociación.

- Sus actos, en consecuencia, son actos administrativos; sus contratos se rigen por el Estatuto General de Contratación Estatal; sus servidores son, por regla general, empleados públicos y por excepción, en cuanto trabajen en la construcción y sostenimiento de obras públicas, son trabajadores oficiales; son sujetos de control fiscal por las contralorías departamentales, si los municipios forman parte de un mismo departamento, o por la Contraloría General de la República, si estos forman parte de distintos departamentos.

- La asociación de municipios interesa fundamentalmente a sus miembros y sólo puede afectar indirectamente el interés general del Estado.

- Las actividades que puede desarrollar en cumplimiento de su objeto se encuentran necesariamente delimitadas con aplicación del principio de la especialidad.

- Sus órganos de gobierno se ciñen a una estructura básica determinada por el ordenamiento jurídico con basamento en un principio de dar participación de sus miembros en consideración y en proporción a su interés. Por ello cuentan con una Asamblea General de Asociados, una Junta Administradora cuyos miembros son elegidos en Asamblea, y un Director Ejecutivo nombrado por la Junta Directiva, quien cumple funciones de representación legal de la asociación.

- El patrimonio y las rentas del sujeto asociativo se conforman y nutren de los recursos que originariamente son de propiedad de los asociados y que estos le transfieren voluntariamente a la asociación.

- Estas características responden adecuadamente a los lineamientos trazados en la Carta de la Autonomía Municipal Iberoamericana de Caracas de 1990, para el estímulo del asociacionismo municipal, como fórmula de "consolidación de los procesos de recuperación municipalista" y de fortalecimiento de la democracia (Villegas, 2002).

Constituye una óptima alternativa de cooperación que permite, no sólo la ejecución de obras de común interés con aprovechamiento de pequeñas economías de escala, sino muy especialmente el adelantamiento conjunto de ejercicios de 
planeación estratégica del desarrollo integral de varios municipios, en especial de los más débiles entre ellos ${ }^{4}$.

La eficacia de esta modalidad corporativa depende, no sólo del análisis de las estadísticas relativas al número de ellas que se ha conformado y al tiempo que ha tenido su existencia, sino también de la verificación cualitativa del cumplimiento de sus objetivos.

En el primer sentido no arroja un mal signo que a finales del año 2009 la Federación Colombiana de Municipios tuviera en sus registros un total de cincuenta y ocho (58) asociaciones de municipios constituidas en la extensa geografía nacional, y únicamente cuatro (4) de ellas inactivas o en estado de liquidación (Moreno, 2009).

En el segundo sentido aunque no se cuenta con estudios disponibles que permitan medir la eficacia de todas y cada una de estas asociaciones, se han producido algunos que constatan la ocurrencia de experiencias, contadas, pero exitosas que trascienden la simple ejecución conjunta de obras y servicios, para internarse en procesos completos y afortunados "de reconciliación, rehabilitación social y desarrollo regional” (Moreno, 2009), en ejercicios válidos de planeación subregional, de gestión crediticia, de seguimiento a la ejecución del gasto y de asesoramiento municipal, entre otros (DNP, 2005).

Estas experiencias han movido a la colaboración de organizaciones internacionales, circunstancia que en alguna medida contribuye a explicar sus resultados, pues no son pocas las dificultades que, en general, enfrentan las asociaciones, dada la precariedad e inestabilidad de sus rentas, la fragilidad financiera de los municipios que las conforman, las exigencias de reducción del gasto municipal, y la alta dependencia que tienen de las agendas de los intereses políticos locales, entre otras debilidades y amenazas que se ciernen sobre su horizonte.

\section{De los distritos}

Sociológicamente, los Distritos son municipios que por su importancia, valor estratégico, o complejidad administrativa se erigen por la Constitución Política como una nueva categoría de entidades territoriales para "sustraerlos del régimen municipal ordinario y dotarlos, en cambio, de un régimen legal especial" (Corte Constitucional, 2009).

4 "La concentración de los ingresos tributarios es muy amplia a favor de los municipios más grandes. Los municipios de más de $500 \mathrm{~m}$ il habitantes que representan el 34\% de la población recaudan el $64 \%$ de todos los ingresos tributarios y si se añade la participación de los mayores de 100 mil habitantes se alcanza un $80 \%$, muy superior a su participación en la población total que es de 55\%" (MALDONADO, Alberto, El sistema municipal y la superación de la pobreza en Colombia. CEPAL, División de Desarrollo Sostenible y Asentamientos Humanos. Proyecto CEPAL (ROA/28), "Pobreza urbana: estrategia orientada a la acción para los gobiernos e instituciones municipales de América Latina y el Caribe", Santiago de Chile, octubre del 2005. 
Jurídicamente, son entidades territoriales, lo que significa que el territorio juega en ellas un papel esencial y constituye, guardada simetría con el Estado, un elemento inescindible de sus habitantes y de las competencias vinculadas a la satisfacción de las necesidades generales y comunes a todos estos, de modo que no limita su razón de ser a la determinación del ámbito espacial del ejercicio de competencias, como ocurre con los entes institucionales. (García de Enterría, 2004).

Por tanto, responden en forma adecuada a la administración especial que demanda un núcleo urbano dotado desde su origen de identidad, pero que por motivo de la complejidad que crean sus particulares condiciones de desarrollo o de crecimiento, debe ser sustraído del régimen general que para la administración de los municipios tiene previsto el ordenamiento jurídico.

Igualmente, puede extrapolarse la aplicación de esta forma de organización a la administración de varios centros urbanos con identidad originaria diversa, pero que como resultado de la conurbación han experimentado una integración plena y han visto desaparecer sus fronteras de todo orden, que da lugar a que irrumpa una nueva unidad, dotada de identidad propia, y de característica complejidad.

Esta excepcional sustracción al régimen ordinario, que revela la estrechez y la vetustez del mismo, se aplicó por primera vez, como ya hubo oportunidad de recordar, para solucionar las problemáticas administrativas sobrevinientes a la conurbación bogotana, dotándola de un régimen político, fiscal y administrativo conformado por las normas constitucionales y legales especiales y por las disposiciones vigentes para los municipios, compatibles con aquellas.

Más tarde, en la agonía de la Constitución de 1886, Cartagena y Santa Marta fueron reconocidas como Distritos, y ya en vigencia de la nueva Constitución, se ha despertado un inusitado interés en varias ciudades por obtener su reconocimiento como distritos. Dos de ellas, Barranquilla y Buenaventura, obtuvieron ese reconocimiento. ${ }^{6}$ Han fracasado en su intento Popayán, Turbo, Tunja y Cúcuta ${ }^{7}$

La indagación sobre el atractivo que puede representar la transformación de los municipios en distritos mueve a pensar que lamentablemente en ello ha jugado papel estelar el beneficio que derivan por causa de tal transformación en el sistema de redistribución de las rentas nacionales, puesto que

"los nuevos distritos no cambian de categoría según las reglas establecidas en la Ley 617 de 2000 y tampoco obtienen ningún tipo de prerrogativa tributaria" (Robledo, 2008).

Aunque su creación corresponde a la ley, todos los Distritos hasta ahora existentes y aquellos que fueron creados pero cuya creación decayó por inconstitucionalidad, lo fueron por acto legislativo reformatorio de la Constitución habida cuenta que aún

5 Actos legislativos 1 de 1987 y 3 de 1989, respectivamente.

6 Acto legislativo 1 de 1993

$7 \quad$ Acto legislativo 2 de 2007 
no se ha expedido la ley orgánica que establezca las bases y condiciones de creación, eliminación, modificación o fusión de entidades territoriales.

Las principales particularidades del régimen de los distritos obran en la ley que apruebe en cada caso su estatuto especial, circunstancia que introduce un interesante margen de flexibilidad y permite, en consecuencia, el diseño de una normativa adecuada a las características particulares de cada municipio o del grupo homogéneo de municipios que por esa normativa se fusiona, que los dote de facultades, instrumentos y recursos propicios para el mejor cumplimiento y prestación de las funciones y servicios a su cargo, para la promoción del desarrollo integral de su territorio y del mejoramiento de la calidad de vida de sus habitantes, a partir del aprovechamiento de sus recursos y ventajas derivadas de sus particulares características, condiciones y circunstancias.

En el caso de Bogotá, su régimen está determinado en el decreto ley 1421 de 1993, y en la caso de los distritos caribeños, en la ley 768 de 2002.

\section{De las Áreas Metropolitanas}

El empleo que ha hecho la legislación de la expresión "área metropolitana", originaria de las ciencias sociales, obliga algunas referencias a su origen y a su doble significación.

\section{Áreas Metropolitanas como fenómenos geo-sociológicos}

La expresión "área metropolitana" tiene su origen en los requerimientos de la actividad censal desplegada a partir de la década de 1940 por la Oficina Federal del Censo de Estados Unidos (Martín Mateo y Otro, 1986) con el propósito de caracterizar adecuadamente a los centros poblacionales más grandes, más densos y de mayor impacto en la vida económica y social bajo la denominación de "Estándar Metropolitan statistical area". Se entendió, para fines censales, como

"condado o grupo de condados contiguos que contiene cuando menos una ciudad de cincuenta mil (50.000) o más habitantes o varias ciudades gemelas con una población mínima acumulada de cincuenta mil (50.000) habitantes"

con inclusión eventual de otros condados contiguos que admitan caracterización metropolitana y se hallen "social y económicamente integrados en la ciudad centro".

A partir de entonces, diversas agencias federales hicieron uso de la expresión, cargándola progresivamente de nuevos elementos, de modo que fue necesario que la Oficina de Presupuesto, y posteriormente la Office of Management and Budget desarrollará esfuerzos para estandarizar su significación en términos que permitieran la comparación de las estadísticas oficiales. Como resultado de estos trabajos, se acordó su significado como

\footnotetext{
"área que contiene un núcleo de población reconocido y las comunidades adyacentes que tienen un alto grado de integración con ese núcleo",
} 
que denota, en su conjunto, una multiplicidad de

"vínculos sociales y económicos entre los núcleos urbanos y las zonas periféricas e integradas" (National Archives and records administration, 2000).

El concepto escapó con rapidez al ámbito puramente estadístico, y se extendió allende las fronteras norteamericanas camino de una polisemia explicable, no sólo por la riqueza funcional del concepto, sino especialmente por las diversas y particulares circunstancias de hecho en las que se les pretende caracterizar, por los divergentes lineamientos que orientan la legislación que las rige en cada país y, por supuesto, por los distintos puntos de vista desde donde las estudia la doctrina (Barrero, 1993).

Objeto, en principio, de estudios disciplinares en especial por parte de geógrafos, sociólogos y economistas, en el propósito de definir, analizar y solucionar los problemas que se derivaban de la conformación de "redes de ciudades", así como de la influencia ejercida por algunas ciudades centrales sobre sus contornos y regiones adyacentes, ha recibido un enfoque interdisciplinar desde mediados de los años sesenta (60) del siglo pasado, que se adecúa en mejor forma a la complejidad que le es característica, tanto como a la aplicación de la teoría de los sistemas para su mejor comprensión (Capel, 2003).

Sin perjuicio del necesario y ulterior retorno sobre estas consideraciones para fines de la propuesta que cierra este trabajo, puede afirmarse que concierne a cada legislación el delineamiento de los contornos socio - geográficos del área metropolitana funcional ${ }^{8}$ como supuesto de hecho de la normativa administrativa que se ocupa de su organización institucional.

En ese sentido, en Colombia, en vigencia de la constitución precedente, el decreto 3104 de 1989 empleó dos elementos para la caracterización esencial de las áreas metropolitanas funcionales: uno, de orden cuantitativo y complejo, consistente en la constatación de una población mínima en el municipio núcleo y en la sumatoria de los habitantes del área total; y otro, de orden cualitativo e igualmente complejo, consistente en la consolidación de una unidad territorial de asentamiento común a los municipios comprometidos y de estrechas relaciones de orden físico, demográfico, económico, social y cultural entre estos, determinantes de una concepción integral del desarrollo y de una necesaria prestación en común de servicios públicos.

Ya en vigencia de la Constitución de 1991, la ley 128 de 1994, apela, para dar forma al concepto, a la idea central de la integración intermunicipal en torno a un municipio núcleo o metrópoli, y a la existencia entre los municipios comprometidos, de estrechas relaciones de orden físico, económico y social, que demanden un

8 Se emplea en este trabajo la disyunción conceptual propuesta por algún sector de la doctrina con aplicación de los adjetivos funcional y legal al nombre complejo de área metropolitana, para caracterizar al supuesto fáctico, y a la institución, respectivamente (DUREAU, F.; C.E. FLÓREZ y M.C. HOYOS. La movilidad de las poblaciones y su impacto sobre la dinámica del área metropolitana, Documento de trabajo No. 1 Bogotá, CEDE-ORSTOM, 1993). 
tratamiento conjunto de la programación y coordinación de sus desarrollos y una programación más racional de sus servicios públicos a cargo.

Como puede apreciarse, la condición nuclear del municipio matriz gravitaba en el primer periodo en torno a su densidad poblacional, mientras que en el segundo la selección del municipio nuclear se dejó abierta, indeterminada, a discreción de los promotores y, finalmente, a la decisión del pueblo, quien avala con el resultado de la consulta popular, tanto la escogencia del municipio núcleo, como el cumplimiento del requisito material de la existencia de estrechas relaciones de orden físico, económico y social entre los municipios y el consiguiente requerimiento de una administración conjunta y coordinada.

\section{Áreas Metropolitanas como instituciones jurídicas administrativas}

La experiencia legislativa extranjera al alcance del legislador material colombiano de 1979, mostraba un paisaje variopinto, no sólo frente a la definición del centro de administración de las áreas metropolitanas, sino en la forma de percibir o establecer la naturaleza de las organizaciones a la que se atribuía dicha tarea.

En el primer punto, algunas legislaciones habían optado por una fórmula anexionista que refundía en un nuevo ente territorial a los municipios involucrados; otras se habían inclinado por atribuir competencias para la atención de los requerimientos de la cotidianidad metropolitana, a órganos centrales de la administración nacional o seccional; otras habían optado por atribuir tales competencias a órganos de la administración del municipio núcleo; y otras más, movidas por un criterio descentralizador, habían optado por crear entes para el desarrollo de las funciones metropolitanas.

A su vez, esta corriente descentralizadora se bifurcaba según se hubiera seguido para el efecto un modelo de descentralización territorial o un modelo de descentralización por servicios o por especialidad. Y, en este último caso, mostraba la experiencia comparada dos variantes: la que aplicaba un modelo típicamente institucional y la que optaba por un modelo corporativo o asociativo.

Pues bien, nuestra legislación ha asumido una postura mixta frente a estas tendencias, si bien desde un primer momento se optó en el decreto 3104 de 1979 por la creación de nuevas entidades para la administración de las áreas metropolitanas.

En efecto, este decreto, a semejanza de lo que dispuso la ley para la constitución de las asociaciones de municipios, hizo depender la puesta en funcionamiento de las áreas metropolitanas, del acuerdo de voluntades de los alcaldes de los municipios interesados, procedimiento que revelaba adscripción al modelo asociativo o corporativo. Sin embargo, con manifiesta inconsecuencia frente al corporativismo adoptado, autorizó también su puesta en funcionamiento mediante acto administrativo unilateral de las Asambleas Departamentales, a la manera de los entes típicamente institucionales. 
La decisión, en uno y otro caso, estaba forzosamente precedida del cumplimiento de requisitos cuantitativos y cualitativos cuya acreditación dependía de certificaciones extendidas por dos órganos de la administración nacional que eran, respectivamente, el Departamento Administrativo Nacional de Estadística y el Departamento Nacional de Planeación, circunstancia que sustraía el asunto del ámbito de la consensualidad.

La organización administrativa interna dispuesta para estos entes, correspondía a las formas propias del modelo asociativo. Constaba de un órgano ejecutivo y unipersonal cuyas funciones desempeñaba el alcalde del municipio núcleo, y otro colegiado y deliberante, en cuya integración se observaba un relativo equilibrio entre el municipio núcleo y el conjunto de los municipios periféricos, al tiempo que participaba en él un representante del Gobernador Departamental en razón de las funciones de coordinación supramunicipal que le eran y son propias, pero también como eventual fórmula arbitral entre el municipio núcleo y los demás municipios miembros.

La preeminencia que confería esta organización al municipio núcleo frente a cada uno de los otros municipios se potenciaba notablemente en la medida en que la preparación y sustanciación de las más significativas funciones y decisiones del área, como lo eran la formulación del plan integral de desarrollo y del programa de inversiones, la coordinación de la ejecución con otras autoridades públicas y la prestación de asistencia técnica a la Junta y al Alcalde metropolitano, se encontraban a cargo de dependencias del municipio núcleo, circunstancia que desnaturalizaba el modelo corporativo y lo aproximaba a aquel otro fundado en la atribución de las competencias metropolitanas al municipio principal.

Los trabajos adelantados en la Asamblea Nacional Constituyente de 1991 sobre la materia, muestran el enfrentamiento desequilibrado y de corto alcance que allí se dio entre dos tendencias: una, que se inclinó inicialmente por el reconocimiento de naturaleza territorial de estas entidades, bajo la denominación de distritos metropolitanos, y otra, que se adscribía en la filosofía corporativista, si bien con los necesarios ajustes en función del redimensionamiento que por consenso habría de reconocerse a las entidades territoriales y particularmente al municipio, a la cual se allanó finalmente la primera.

La debida consecuencia de la ley 128 de 1994 con la irrestricta adhesión al principio de la democracia participativa y al marcado municipalismo profesado por la Constitución de 1991, se tradujo en significativos avances en el reconocimiento de la autonomía municipal frente al proceso de constitución de estas entidades y en un tímido paso adelante en el reconocimiento de su naturaleza y en la coherencia de su organización corporativa.

Uno y otro rasgo se pueden percibir en el procedimiento previsto para su constitución y en la normativa dispuesta para su organización interna. Su constitución no puede llevarse a cabo en forma unilateral y depende hoy, al igual que la vinculación de un nuevo municipio o la desvinculación de uno que ya forme parte del área, exclusivamente de instancias locales, pues la iniciativa puede tener origen 
en los alcaldes de los municipios interesados, en la tercera parte de los Concejales de dichos Municipios, o el en cinco por ciento (5\%) de los ciudadanos que integren el censo electoral de los mismos; de la aprobación del proyecto por el voto afirmativo de la mayoría de los sufragantes en consulta al pueblo en la totalidad de los municipios interesados; y de la protocolización del acuerdo de conformación con intervención de los alcaldes y presidentes de los concejos municipales correspondientes. Su Organización interna tiene en su base una Junta Metropolitana cuya integración responde en mejor forma al principio de la representación indirecta por cuanto "permite la participación en ella de todos los municipios integrados" (Castillo, 1999), que disminuye sin eliminarla, la desigualdad de trato que en la materia existía en la legislación en la legislación anterior entre el municipio núcleo y cada uno de los municipios periféricos, en cuanto dispone su integración por todos los alcaldes de los municipios que la integran, un representante del concejo del municipio núcleo, un representante de los concejos de todos demás municipios, y un representante del gobernador o el secretario o Jefe de Planeación Departamental.

El articulado de la ley 128 de 1994 y algunas disposiciones de otras leyes que aluden a ellas, permite caracterizar a las áreas metropolitanas legales en los siguientes términos:

- Son personas jurídicas de derecho público que se constituyen por decisión popular de los ciudadanos que habitan los diferentes municipios interesados, subseguida por la protocolización, en plazo perentorio, del acto de conformación por parte de los Alcaldes y Presidentes de los Concejos de tales municipios.

- Responden a la necesidad reconocida por los ciudadanos que las habitan, de coordinar y programar el desarrollo del conjunto de municipios integrados y de racionalizar la prestación de los servicios que originariamente se encuentra a cargo de estos, de modo que la legislación asume que tales actividades, de no crearse una nueva entidad, deben y pueden ser realizadas en forma individual y en sus respectivos territorios por cada uno de los municipios que se encuentran integrado geográfica y sociológicamente.

- Como expresión reconocida de la autonomía individual de los municipios, compete a éstos acordar el nombre que ha de darse a la entidad y "las funciones generales que cumplirá el ente metropolitano, particularmente en materia de planeación, obras, servicios públicos y obras de desarrollo económico y social (art. 5 núm. 6 de la ley).

- Su régimen jurídico se remite integralmente al derecho público.

- El lindero que separa el ámbito material de su competencia funcional del quehacer estrictamente municipal se encuentra definido en abstracto por la ley en relación con los hechos que afecten simultánea y esencialmente a por lo menos dos de los municipios que integran el área como consecuencia del fenómeno de la conurbación, expresión que emplea la norma para aludir indistintamente a la conurbación y a la metropolización. Como un 
tributo a la autonomía de la entidad, la ley ha depositado un alto grado de discrecionalidad en la Junta Metropolitana para la definición en concreto de estos "hechos metropolitanos".

- La estructura básica de su organización interna está definida por ley en los niveles de gobierno y administración y asesor. Como órganos de gobierno y administración, además de la Junta Metropolitana, que es el principal entre ellos, cuenta con el alcalde metropolitano y un Gerente. Como alcalde metropolitano funge el alcalde del municipio núcleo y sus funciones son de convocatoria, iniciativa, reglamentación y ejecución en relación con las sesiones y decisiones de la Junta Metropolitana. El Gerente, por su parte, es un empleado público nominado discrecionalmente por el Alcalde Metropolitano y tiene por función la dinamización de la actividad externa del área en ejercicio de las atribuciones de representación legal.

- El patrimonio y las rentas del sujeto asociativo se conforma y nutren de recursos mayoritariamente de origen contributivo, consistentes, de una parte, en la sobretasa al impuesto predial $^{9}$ y en la sobretasa a la gasolina ${ }^{10}$, y de otra parte en la contribución de valorización. A estos se suman los recursos procedentes del servicio a manera de derechos o tasas remunerativas, los recursos que le sean transferidos del presupuesto de los entes territoriales y de sus entidades descentralizadas por servicios, los recursos del crédito, el producido de sus rentes y patrimonio, las donaciones y los demás bienes que adquiera a cualquier título.

9 Respecto de esta renta, la Corte Constitucional ha precisado que "las áreas metropolitanas podrán ser destinatarias del porcentaje sobre el impuesto predial, con la condición que estén encargadas por la ley "del manejo y conservación del ambiente y de los recursos naturales renovables" y que en la misma jurisdicción no actúen otras entidades encargadas de las mismas atribuciones" (C-1096/01, reiterada en C-093/02). En este sentido, el literal C del artículo 14 de la Ley 128 de 1994 atribuye a la Junta Metropolitana, en relación a los recursos naturales y al medio ambiente, la competencia para adoptar, si no existen Corporaciones Autónomas Regionales en la totalidad de su jurisdicción, un plan metropolitano para la protección de los recursos naturales y defensa del ambiente, de conformidad con las disposiciones legales y reglamentarias sobre la materia. Por su parte, la Ley 99 de 1993 o Ley Ambiental, reconoce a las Áreas Metropolitanas como autoridades ambientales en la zona urbana que comprende su territorio sólo cuando su población urbana sea igual o superior a un millón de habitantes

10 En relación con la sobretasa a la gasolina, sin embargo, ha de tenerse en cuenta que esta renta tiene por titular a los municipios y distritos y que el artículo 22 literal j de la Ley 128 de 1994 "lo que hace es obligar a las entidades territoriales que integran un área metropolitana a transferir los recursos de la sobretasa a la gasolina cobrados en la jurisdicción del área, si y sólo si se cumplen las condiciones legales para ello (Ley 86 de 1989), a saber que adelanten un proyecto orientado a implementar en su jurisdicción un Sistema Masivo de Transporte de Pasajeros o que se apliquen a materias afines según las leyes que regulan la sobretasa dentro de la órbita de competencia del área metropolitana" (C-1175-01). 


\section{Consideraciones previas a una propuesta}

Una revisión crítica de la normativa legal atinente a las áreas metropolitanas debe abordar, cuando menos, los siguientes aspectos: la pertinencia de la concepción de área metropolitana funcional que subyace al ordenamiento legal, la consecuencia observada en la definición de la naturaleza del ente que las organiza, la coherencia del marco competencial establecido para las áreas metropolitanas, y la suficiencia de su régimen patrimonial.

Ha de asumirse, como punto de partida, que tal cual lo reseña la doctrina foránea, la definición de la naturaleza de las áreas metropolitanas ha sido en el derecho comparado terreno fértil para la diversidad, la atipicidad, la "originalidad buscada con deliberación" (Santamaría Pastor, 1991).

No es asunto fácil, pero tampoco es un propósito baladí el definir la naturaleza de los hechos y fenómenos sociales. Basta recordar las múltiples teorías que se han esbozado a través de los tiempos en el propósito de explicar la naturaleza del municipio, para comprender la dimensión del trabajo que en relación con las áreas metropolitanas ha de emprenderse. De seguro, se verán replicadas y aún multiplicadas las teorías sobre el origen y naturaleza del municipio al momento de definir la esencia misma de las áreas metropolitanas, pero esto lejos de mover a desmayo, debe estimular una labor cuyos frutos no se cosecharán ciertamente en el consenso, tanto como en la consecuencia.

El punto se remonta a los primeros efectos de la revolución industrial sobre la vida urbana de los pueblos y a la consiguiente irrupción de la metrópolis industrial moderna (Soja, 2000), cuya denominación evoca en su etimología la relación que se establece entre una ciudad y otros núcleos poblacionales menores, en la que el rol de aquella frente a estos se asimila al rol materno (Henao, 1995).

Sus perfiles característicos se descubren en la quiebra de la unidad y límites físicos de la ciudad legada por el Medievo, por causa de la densificación y concentración poblacional, de la extensión espacial y de la fragmentación urbana (Lázaro, Torres et al. 1998).

Los estudios sobre la metrópoli son de variada gama y perspectiva. Algunos se ocupan del análisis del influjo e impacto de diversa índole que ejerce la metrópoli sobre el entorno rural, otros centran su atención sobre las dinámicas de movilidad poblacional entre el núcleo y la periferia y viceversa; hay quienes, desde otra óptica, estudian las relaciones de producción y consumo en doble sentido (Capel, 2003) y otros más, se detienen a examinar las implicaciones que esa multiforme red de relaciones tiene sobre la eficacia de la administración pública, tanto en su tradicional función policiva, como en su condición de dispensadora de servicios públicos ${ }^{11}$.

11 Ver un recuento de los principales trabajos realizados al respecto en CAPEL, Horacio. Una mirada histórica sobre los estudios de redes de ciudades y sistemas urbanos. GeoTrópico, 1 (1), 30-65, versión PDF. Online: http://www.geotropico.org/1_1_Capel.html. 
Desde este último punto de vista, resulta preciso diferenciar los requerimientos de administración que sobrevienen a las relaciones emergentes entre núcleos poblacionales claramente diferenciables, con identidad particular y administraciones de contornos reconocibles, de aquellos que surgen a consecuencia de la atenuación progresiva de los perímetros que otrora demarcaron territorialmente sus ámbitos individuales.

Aquellos pueden afrontarse con una debida agudización de idoneidad administrativa de cada municipalidad, y optimizarse con recurso a la asociación. Estos, a contrapelo, desbordan definitivamente la capacidad administrativa de cada una de las administraciones locales involucradas, pues, como corolario de la unión de un número plural de centros poblacionales de similar status, como ocurre con las formas bipolares o multipolares de aglomeración, para las que algún sector de la doctrina (Precedo Ledo, 1988) reserva la denominación sustantiva de conurbaciones; o "merced a la fuerza cohesiva que emana desde su centro", como ocurre en las metropolizaciones,

"el área tributaria en cuestión adquiere tal grado de homogeneidad que bien se la puede considerar como una unidad social natural" (Dickinson, 1947).

Es esta unidad social natural una modalidad especial y cualificada de conglomeración urbana que se conoce con el nombre de área metropolitana. Por ello, desde el punto de vista que interesa al derecho, esta es una denominación que

\footnotetext{
"debe quedar reservada a aquellos supuestos en los que ese ámbito territorial abarca centros poblacionales urbanos cuyos límites aparentemente han desaparecido en medio de las fuertes vinculaciones económicas, sociales y urbanísticas" (Barrero, 1993)
}

que se traban entre sus habitantes sin consideración a su locación de origen, bien que esto haya ocurrido por la fuerza de convocatoria de un núcleo urbano principal o por la expansión de varios centros poblacionales de similar status.

Dicha unidad social natural es fuente de necesidades que escapan a la capacidad de gestión administrativa de las autoridades de cada uno de los municipios, comoquiera que atañen a un nuevo "interés general" que tiene por titular a la población conglomerada, y que no siempre coincide con el interés de cada comunidad municipal que resulta integrada en ella, sin que por esto pueda decirse que necesariamente han desaparecido las comunidades locales o han cesado las necesidades que tienen por sujeto a cada una de estas.

Este nuevo interés general bien puede, en un estado ideal de cosas, atenderse con espíritu de cooperación y con el consiguiente recurso a la asociación de los entes municipales comprometidos. Pero al margen del ideal, por esta vía la realidad bien pronto mostrará que los intereses de las comunidades municipales, así como los intereses sectoriales existentes en cada una de ellas, tienen fuerza y dinámica capaz de enervar los propósitos de satisfacción del interés general del área socio geográfica integrada, para generar crisis de gobernabilidad con afectación, allende sus precisos contornos de la región y aún del interés nacional. 
Nuestra legislación ha organizado las áreas metropolitanas con rasgos preponderantemente corporativistas. Así, se ha mostrado en apartes precedentes de este trabajo, y así lo ha interpretado nuestra Corte Constitucional, órgano que con ocasión de la descripción del conjunto de entidades públicas existentes en el orden territorial ha dicho:

\begin{abstract}
"En el nivel territorial coexisten diferentes personas jurídicas de derecho público, las cuales obedecen a lógicas distintas de organización. Unas corresponden a la organización política del Estado (las entidades territoriales), algunas a la descentralización por servicios (entidades descentralizadas) y otras al resultado de la asociación entre entidades territoriales (asociaciones de municipios, áreas metropolitanas y regiones administrativas y de planificación) y, todas ellas cuentan con su propia personalidad jurídica, la cual apareja consigo el reconocimiento de autonomía administrativa, autoridades y patrimonio propios" (C-1096/01).
\end{abstract}

El balance que arroja esta legislación desde la perspectiva de su eficacia, constituye, sin embargo, un indicio grave de la impertinencia de esta adscripción al corporativismo.

Es así como, a despecho de la real existencia en el territorio patrio de más de una decena de áreas metropolitanas funcionales, bastan los dedos de una mano para nombrar las áreas metropolitanas legales que han sido organizadas y puestas en funcionamiento después de cuarenta y dos (42) años de su autorización por parte del ordenamiento constitucional. De hecho, las entidades de esta especie que se crearon bajo la Constitución anterior, nacieron bajo el impulso del Estado Central y con notables y sonoros desacuerdos de los municipios miembros, algunos de los cuales debieron ser resueltos, finalmente, con la intervención de la jurisdicción contencioso administrativa; y las que se han creado en vigencia de la Constitución de 1991, no han podido entrar en funcionamiento por falta de voluntad política de las autoridades de los municipios que las conforman.

Pero, más allá de este hecho, las pocas áreas metropolitanas existentes y en operación, se duelen de la falta de los más elementales presupuestos de funcionalidad, se encuentran sumidas en una condición que las hace ajenas a los destinatarios de sus competencias, han creado una brecha que se ensancha en la medida en que merced al voluntarismo al que se ha marginado la definición de los hechos metropolitanos, los habitantes de las áreas metropolitanas perciben frecuentemente su accionar, de suyo gravoso, dado que se suele financiar con recursos de valorización, como invasivo de la vida de sus propios municipios, o lo que es peor, como inclinado al favorecimiento de los intereses del municipio núcleo.

Tan nefastos vicios se encuentran entrañablemente relacionados y tienen su causa en el delineamiento legal que del fenómeno del "hecho metropolitano" lo ha hecho el legislador colombiano en términos altamente abstractos (Castillo, 1999) que pueden y suelen ser desnaturalizados por las Juntas Metropolitanas en dos sentidos: desvían el accionar de las áreas metropolitanas hacia la ejecución de actividades 
estrictamente municipales, con grave detrimento de su legitimación o, lo que puede ser peor, abandonan el tratamiento de auténticos hechos metropolitanos al ámbito ineficiente de la administración estrictamente municipal, con grave compromiso de la gobernabilidad. A manera de ejemplo de este último vicio, viene al caso el problema de la movilidad que ha sobrevenido en áreas metropolitanas en las que las autoridades de los diferentes municipios han adoptado decisiones contradictorias en materia de restricción vehicular en determinadas horas del día.

Conviene, entonces, revisar la legislación existente, no sólo con el propósito de quebrar el sesgo corporativo que tiene, sino de corregir las consecuencias que transmite sobre la determinación del ámbito competencial de las áreas metropolitanas, sobre la integración y conformación de sus órganos de administración y gobierno y sobre su autonomía patrimonial.

En estos últimos aspectos, el sistema de representación democrática indirecta que rige actualmente la integración de la Junta Metropolitana por Concejales de los Municipios miembros, hace a estos órganos altamente vulnerables a la influencia política de los estamentos locales (BRC, 2006 y 2007); y la falta de competencias impositivas propias, las hace depender en el gasto y en la inversión, que no pueden financiar vía valorización, de rentas cuyo recaudo se encuentra a cargo de terceros (BRC, 2006, 2007).

No menos importante resulta, aunque exceda los alcances de este trabajo, la revisión de la articulación que debe promoverse, del accionar planificador metropolitano con los ámbitos regionales y nacionales de planeación, si se considera que la Ley Orgánica de Planeación, que tiene por objeto principal establecer los procedimientos y mecanismos para la elaboración, aprobación, ejecución, seguimiento, evaluación y control de los planes de desarrollo a nivel nacional y territorial,

\begin{abstract}
"no tuvo en cuenta a las áreas metropolitanas como actores del sistema de planificación, produciéndose grandes dificultades para articular la planificación de municipios con figuras supramunicipales diferentes al departamento" (Carrión, 2009).
\end{abstract}

\title{
Provisiones para la revisión del tipo organizacional
}

La propuesta sobre este particular se limita a la formulación de planteamientos y diseños básicos de constitución y organización, definidos en atención a la necesidad de privilegiar el interés general metropolitano sobre el interés de los fortines políticos municipales, cuando así lo impone la realidad geo-socio-económica; de introducir criterios económicos que estimulen la competitividad de los conglomerados como presupuesto de su inserción en la economía global; y de desarmar, a un mismo tiempo, a los espíritus que escudan su antipatía por las instituciones supramunicipales en un pretendido y no siempre genuino celo municipalista.

Parte de una somera reconstrucción de la tipología de las organizaciones públicas a las que se reconoce capacidad de goce de derechos, en cuanto permite distinguir 
entre entidades territoriales y simplemente administrativas, al tiempo que en este último género permite diferenciar entre entidades administrativas institucionales y entidades administrativas corporativas.

En ese preciso contexto, al margen del corporativismo, el modelo organizacional de las áreas metropolitanas ha de buscarse entre las entidades territoriales y los entes administrativos institucionales.

Milita, en favor de la primera opción, el diagnóstico previo de la naturaleza del área metropolitana funcional, en cuanto indica que hay allí, de facto, un espacio, una población y unos hechos que trascienden el ámbito de lo estrictamente municipal, y que pueden darse, incluso, sin consideración al ámbito propio de un determinado departamento, circunstancia que motivó una de las más relevantes reformas que introdujo en la materia la ley 128 de 1994.

Hay allí, también, unas necesidades en las que tiene interés la población conglomerada, que afectan el espacio por ella ocupado, superan la capacidad y escapan a la competencia de las autoridades de cada uno de los elementos municipales inmersos en la realidad metropolitana, pues sus dolientes ni tienen asentamiento habitacional, ni despliegan sus actividades básicas y cotidianas en el territorio de un solo municipio, ni satisfacen sus necesidades integralmente en una sola y única circunscripción municipal, sino que la sumatoria de dichas circunstancias vitales discurre en un solo espacio integral supramunicipal ${ }^{12}$.

Para su satisfacción no sólo resulta necesario crear órganos propios y diferentes de los órganos de las administraciones de las municipalidades comprometidas, afectos como se encuentran ellos a la satisfacción de su interés particular, sino que dichos órganos deben tener por sustancia unas funciones que guarden relación directa y necesaria con esas necesidades objetivas preexistentes.

No basta todo esto, sin embargo, para inclinar definitivamente la balanza en favor de la opción de reconocer en las áreas metropolitanas a una nueva entidad territorial. Es preciso verificar si se configura en el área metropolitana funcional una nueva identidad como resultado de la fusión del territorio y de la población que lo habita, en forma tal que las necesidades que concierna satisfacer al ente metropolitano sean generales y comunes a sus miembros y que nada de lo que interesa a cada uno de ellos en el ámbito local resulte extraño al quehacer de dicha entidad.

En ese propósito, conviene reparar en la diferencia existente en los variados tipos posibles de conurbación, integración e interrelación municipal que pueden presentarse.

12 Sin embargo, una fiel individualización de las áreas metropolitanas debe suponer la pervivencia simultánea de intereses estrictamente municipales al lado de la cantera emergente de intereses metropolitanos, como se infiere de la precisión que se hace en la conceptualización del área metropolitana funcional al aludir a la aparente desaparición de los límites municipales, pues en caso de desvanecerse aquellos, se habrá producido una fusión cuyo tratamiento podría encausarse en nuestro ordenamiento a través de la institución del Distrito. 
Una debida categorización de las más importantes modalidades de interrelación e integración que se presentan en la vida local contemporánea, debe considerar por aparte los casos de interrelación entre sujetos municipales capaces de desempeñar individualmente y con eficiencia relativa sus funciones, sin perjuicio de las potencialidades de optimización derivadas de la cooperación intermunicipal, de aquellos otros casos en los cuales la eficiencia administrativa resulta comprometida por la existencia de flujos recíprocos o unidireccionales de actividad entre los habitantes de diversos municipios, capaces de afectar, tanto el ordenado y armónico desarrollo de cada uno de ellos y de todos ellos en conjunto, como a la racionalidad que demanda la prestación de los servicios públicos.

El primer escenario mueve a la cooperación voluntaria -si no resulta reiterativa la idea- al tanto que el segundo puede buscar cauce organizacional diverso, según la intensidad del proceso de integración o conurbación que revele cada caso particular.

El mayor grado de intensidad se presenta en las conurbaciones o integraciones plenas, vale decir, cuando estos fenómenos provoquen el desvanecimiento de los límites existentes entre la ciudad metrópoli y los demás asentamientos urbanos periféricos o entre diversas ciudades o asentamientos urbanos de igual status.

Un grado moderado de intensidad se presenta en los casos en los que la conurbación o integración plena se avizora a corto o mediano plazo como previsible por causa de las fuertes vinculaciones económicas, sociales y urbanísticas que se traban entre sus habitantes sin consideración a su locación de origen, en la medida en que éstas generan

"extensas interdependencias funcionales, amplio mercado laboral y oferta profesional diversificada, concentración espacial de externalidades, efectos de desbordamiento, y un ecosistema humano con identidad distintivamente homogénea" (Cuadrado Roura, Fernández Güel, 2005)

Y un grado leve de intensidad se puede predicar en casos en los que, varios municipios vecinos de igual o similar status que no se encuentran conurbados entre sí, acusen moderada y relativamente estable integración económica y social que demande, con visión de futuro, una planeación conjunta del desarrollo incardinada hacia la creación de condiciones propicias para la inserción de la región urbana en la economía nacional o global.

En lo que respecta al modelo cooperativo, recomendable para el último de los escenarios previstos, la forma organizacional pertinente será la asociación de municipios, en cuanto constituye el tipo de organización apta para articular fortalezas y oportunidades, conjurar riesgos y superar debilidades en el ejercicio de funciones municipales que de suyo pueden desempeñarse individualmente, pero que pueden derivar mayores márgenes de eficiencia en escenarios de cooperación entre sujetos de igual o similar status. En estos casos, tanto la iniciativa, como la decisión deben dejarse a la autonomía municipal. Su régimen jurídico actual se muestra idóneo para el logro de los fines que ellas persiguen, aunque debería estimularse esta modalidad de cooperación y privilegiar la asignación de recursos de fomento y la vinculación 
del Departamento y de la Nación a proyectos que demanden cofinanciación, cuando sean presentados por asociaciones de municipios.

La iniciativa gubernamental en la materia ha sido recurrente. De hecho, recientemente, los medios de comunicación han reseñado el registro que ha hecho el nuevo gobierno en el Congreso de la República, por decimonona vez, del proyecto de Ordenamiento Territorial, entre cuyas tendencias se observa, precisamente, el estímulo para que los municipios accedan a los recursos de la Nación cuando se unan en asociaciones o federaciones (El Colombiano, 2010).

Los eventos de conurbación o integración plena, por su parte, en cuanto han dado lugar a una nueva identid ad, deben dar lugar a la creación de una entidad territorial, a la manera de los Distritos, que bien podrían recibir el apelativo común de Distrito Metropolitano, con atribuciones plenas para la planeación del desarrollo, la planeación territorial, la reglamentación, y la ejecución del gasto distrital, sin perjuicio de la reserva de iniciativa, y de la creación de razonables y normados espacios de desconcentración de las actividades de ejecución en órganos de las localidades. $\mathrm{Su}$ organización institucional, en cuanto responde a requerimientos que trascienden, aún involucrándolo, el interés individual de las municipalidades originarias, resulta aconsejable reservarlo al legislador, sin perjuicio del reconocimiento de iniciativa popular para la promoción de referendos distritales derogatorios de la ley que demanden altos índices de participación y amplias mayorías para su aprobación. Su organización básica se aconseja binaria, con un órgano deliberativo y colegiado y otro unipersonal y ejecutivo, cuyos miembros y dignatario, sean elegidos con procedimientos de democracia directa en jurisdicción única.

Los casos de conurbación o integración moderada, han de tratarse con algunos matices diferenciados en función del número y dirección de los vectores que provocan estos fenómenos, vale decir, que sin perjuicio de su comunidad de régimen, se disponen algunas normas especiales, tanto para los casos en los que los procesos de integración tengan origen en la fuerza de convocatoria de un núcleo urbano principal, como para aquellos en los que los procesos de integración y/o conurbación deban su dinámica a la propensión expansiva de varios núcleos de similar status.

Esta integración o conurbación moderada constituye el eje central de las áreas metropolitanas legales, cuyos elementos característicos pueden resumirse así: la conformación en presente de un ecosistema humano con identidad distintivamente homogénea; la existencia actual de extensas interdependencias funcionales entre los municipios que la conforman; y la tendencia a un futuro de integración plena como resultado de un proceso de conurbación en curso.

El primero de ellos aproxima a las áreas metropolitanas legales a la naturaleza de las entidades territoriales, no obstante lo cual, podría argumentarse, en sentido contrario, que el escenario de futuro muestra que aún no se consolida la integración y la consiguiente unidad territorial, elemento característico de estas últimas y que, por tanto, en el mejor de los casos se puede decir, que son una suerte de entidad 
territorial en proceso, cuyas funciones admiten aún algún margen de especialidad ya que la metropolización no afecta necesariamente la universalidad de los fines que atañen al interés local en términos que admitan concluir que "nada de lo que afecte a las personas que habitan dentro de su territorio les pueda resultar ajeno" (García de Enterría, 2004).

Esta circunstancia dificulta, ciertamente, la derivación de consecuencias absolutas a una hipotética consideración de las áreas metropolitanas como entes territoriales, al menos con el alcance y la significación que la norma constitucional vigente les reconoce, dificultad cuya superación podría procurarse por el camino de reconocer en los entes en cuestión la condición de entidades territoriales especiales, de segundo grado, que el ordenamiento constitucional no reconoce aún.

Pero esta línea tampoco conduce a un terreno pacífico, pues si se les reconociera constitucionalmente como entes territoriales de segundo grado, traicionada la esencia de la federación podría proponerse su organización sin intervención de la voluntad de quienes se federan, tanto en lo que respecta a tal decisión constitutiva, como en lo que atañe a la delimitación de las competencias a trasladar del municipio al nuevo ente.

Así las cosas, restaría, por residuo, consultar la pertinencia del tipo institucional, alternativa que tampoco admite plena consecuencia, pues los entes públicos institucionales tienen como característica su condición instrumental o auxiliar respecto del ente que los crea (Giannini, 1991), de forma que su creación legal u ordenanzal, comporta una centralización territorial de los asuntos locales, ajena al espíritu de la Constitución.

Entonces, parecería que la definición ideal del tipo al que deben pertenecer, condena a las áreas metropolitanas al hibridismo y al reconocimiento de una naturaleza sui generis que participe de los caracteres básicos del tipo institucional en su creación, en el señalamiento de sus fines y competencias y en el delineamiento de sus órganos fundamentales de administración interna, pero cuya condición instrumental se diluya con el reconocimiento de un alto grado de autonomía, que le permita a los habitantes del área participar, mediante procedimientos de democracia directa, en la elección de los miembros del órgano colegiado de reglamentación, como ocurre tratándose de entidades territoriales, y le asegure a la institución el derecho a ejercer sus competencias sin injerencia endógena, así como el derecho a unas rentas y a un patrimonio suficientes, no sólo para la ejecución de obra y prestación de servicios metropolitanos, sino, especialmente, para el adelantamiento de las tareas de planeación que le son propias y demandan ingentes "costos hundidos" que no admiten recuperación vía valorización.

Conviene, sin embargo, diferenciar el régimen de gobierno y administración, en atención al proceso que ha dado origen al área. Si ésta es resultado de una metropolización, el peso que soporta el municipio núcleo en las cargas que de tal proceso se derivan, haría más equitativo que el órgano deliberativo y colegiado estuviera integrado por miembros elegidos en circunscripciones municipales en 
número que guarde alguna proporción atenuada, no necesariamente aritmética, con la relación existente entre el número de habitantes de cada uno de ellos y el total de la población del área.

Tratándose de áreas metropolitanas resultantes de procesos típicos de conurbación, el similar status de los municipios que las integran permite que los miembros del órgano deliberativo y colegiado sean elegidos democrática y directamente, en circunscripción única metropolitana.

En uno y otro caso, debería advertirse que el órgano ejecutivo está llamado a cumplir funciones preponderantemente técnicas, razón por la cual, su nombramiento puede ser competencia de la Junta o Consejo Metropolitano, preferiblemente, mediante acto reglado y previo procedimiento fundado en el principio del mérito.

Provisiones para la caracterización del "hecho metropolitano" y la definición del ámbito funcional metropolitano

A la luz del artículo 319 de la Constitución vigente, las áreas metropolitanas tienen por funciones, en primer lugar, la programación y coordinación del desarrollo armónico e integrado de su territorio; en segundo lugar, la racionalización de los servicios públicos a cargo de los municipios que las integran, y la ejecución de obras de interés metropolitano; y sólo de manera residual y eventual, la prestación en común de algunos de los servicios públicos a cargo de los municipios miembros, circunstancia que guarda plena coherencia con el derecho que se reconoce a los municipios, a la luz del artículo 287 de la Constitución, al ejercicio de sus propias competencias.

La ley 128 de 1994, o ley orgánica de las áreas metropolitanas, por su parte, despliega ese objeto, a manera de atribuciones a cada uno de los órganos internos del área, asigna las más importantes, entre las misionales, al órgano colegiado y deliberativo. Entre estas, sobresalen las siguientes:

- Planeación integral del desarrollo, y planeación específica vial, de servicios, de obra y de protección de recursos naturales y del medio ambiente, esto último en subsidio de las Corporaciones Autónomas Regionales;

- Reglamentación general de los usos del suelo y de los perímetros urbano, suburbano y sanitario de los municipios miembros; y del régimen de valorización metropolitano.

- Coordinación del sistema nacional de vivienda de interés social en su territorio;

- Orientación con fines de armonización tarifaria, a los municipios, en materia de política fiscal y financiera.

- Declaración de utilidad pública o interés social y afectación de inmuebles para fines de desarrollo y de obra metropolitana

- Determinación del carácter metropolitano de algunos servicios locales y aseguramiento de su adecuada prestación. 
- Ejecución de obras metropolitanas.

Ahora bien, las funciones institucionales de programación y coordinación del desarrollo armónico e integrado de su territorio y de ejecución de obra pública, y las competencias que las detallan, son de carácter local y demandan, en consecuencia, una adecuada separación frente a la esfera funcional de los municipios, tarea que resulta decisiva, no sólo para la funcionalidad del área metropolitana, sino para su propia legitimidad, y en la que juega un papel determinante la noción hecho metropolitano.

Esta expresión compuesta, puede analizarse semánticamente a partir del significado de cada uno de sus elementos. En cuanto al hecho, alude a todo acontecimiento o suceso con independencia de su origen, esto es, sin que interese que sea consecuencia de la naturaleza o del comportamiento humano, y en cuanto a la calificación metropolitano, refiere a su capacidad de generar efecto en una escala supramunicipal, en relación con varios municipios afectados por procesos de conurbación o de metropolización y por causa de estos.

En tal sentido, no hay razón suficiente para discutir la pertinencia que en abstracto tiene la definición que hace la legislación actual del "hecho metropolitano", como hechos que afectan simultánea y esencialmente a por lo menos dos municipios integrantes del área como consecuencia de la conurbación (en sentido lato), si bien ésta admite una mayor cualificación.

El mayor inconveniente surge, en realidad, del aparte de la noción legal que aquí se ha omitido, esto es, del abandono de su concreción, en cada caso particular, a la discreción del órgano colegiado de gobierno del área, pues lejos de producir el efecto deseado, el dejar en manos de los representantes de las municipalidades tal definición, ha conducido a un escenario más propicio para la defensa del interés del sujeto municipal agenciado, que para la primacía del interés general de los habitantes del área metropolitana.

En el contexto de esta propuesta, el asunto adquiere una doble novedad, pues, de un lado, la definición se sustrae del capricho de los órganos metropolitanos, al ser objeto de una más precisa regulación legal; y de otro lado, su concreción por parte del órgano colegiado y deliberativo, será el resultado del ejercicio de una competencia reglada, por órgano integrado mediante procedimientos de democracia directa, más favorables a la genuina representación de la colectividad conglomerada.

Ha de admitirse que no es tarea fácil la definición legal y exhaustiva del concepto, pues aparte la complejidad consustancial al fenómeno metropolitano, ha de tenerse la doble prevención aneja a toda definición: evitar que elementos del hecho metropolitano queden excluidos de sus límites y que, simultáneamente, hechos estrictamente municipales ensanchen injustificadamente sus contornos.

En primer lugar, el concepto debe partir de la consideración básica del carácter estrictamente local de las materias que conforman el contenido de las competencias, circunstancia que obliga a tener especial cuidado con las consecuencias que se 
desprenden de la fórmula unitaria que preside a la caracterización de nuestro Estado.

En segundo lugar, debe respetar de manera estricta la reserva funcional que la Constitución política haga de las materias a cargo de los municipios.

En tercer lugar, debe proyectarse sobre aquellas aristas funcionales que el artículo 319 atribuye a las áreas metropolitanas allende el ámbito estrictamente municipal. En tal sentido, sólo dos de ellas configuran dicho supuesto: la planeación, programación y coordinación del desarrollo de su territorio y la ejecución de obras públicas metropolitanas.

Con estas previsiones, procede el delineamiento de los caracteres generales de las hipótesis fácticas que imprimen contorno metropolitano a una determinada actividad o suceso.

A guisa de ejemplo $\mathrm{y}$, sólo como punto de partida de un trabajo de conceptualización que recoja estas recomendaciones, se propone la siguiente noción:

Son hechos metropolitanos todos los acontecimientos o sucesos naturales o humanos capaces de generar efectos en el suelo, en los recursos naturales y en la infraestructura pública de uso común a los habitantes de dos o más municipios inmersos en procesos de conurbación o metropolización; de perturbar la ordenación armónica de los usos del suelo que ha sido dispuesta para el corto o mediano plazo por dichos municipios; de afectar significativamente en el corto plazo los indicadores de desarrollo de dos o más de ellos; o de alterar las condiciones históricas comparativas de la demanda y de la oferta de servicios municipales con quiebra del margen de simetría que han observado los municipios en promedio en los veinte años precedentes. Son hechos metropolitanos, entre otros, los siguientes ${ }^{13}$ :

1. Los que afectan las condiciones de mantenimiento y uso de vías nacionales, regionales y arteriales que necesariamente deban ser utilizadas por los habitantes del área metropolitana para desplazarse de uno a otro municipio dentro de la misma, o que contribuyan a descongestionar la movilidad entre dos o más municipios del área.

2. Los que perturban la atmósfera, el suelo y/o las corrientes de agua comunes a dos o más municipios del área metropolitana, mientras no constituyan el objeto de la competencia de una autoridad ambiental.

3. La determinación de los lineamientos generales, que a manera de objetivos y criterios, han de orientar la definición de los usos del suelo por parte de los municipios involucrados en el área metropolitana.

4. La provisión y equipamiento de espacios públicos y la construcción de obras públicas que estén llamadas a prestar inequívoco servicio a la totalidad de los habitantes del área metropolitana, circunstancia que se presume cuando

13 Se toman como ejemplos, aunque con mayor detalle, algunos de los hechos que describía el proyecto de ley que dio origen a la ley 128 de 1994 en un aparte del mismo que fue suprimido en el trámite del proceso legislativo y que transcribe CASTILLO GALVIS Mary Eugenia en su obra, ya citada. 
la obra pública se construye, y el espacio público se extiende, de manera continua por suelos de más de un municipio del área.

5. La coordinación de las actividades de los municipios conducentes a la constitución de empresas de servicios públicos domiciliarios de radio metropolitano.

6. La construcción de centros mayoristas y públicos de mercadeo y la prestación directa de servicios de plantas de sacrificio de ganado cuandoquiera que ninguno de los municipios del área preste este servicio en condiciones de eficiencia y con sujeción a los parámetros legales y reglamentarios del servicio, o acredite el registro de un proyecto financiado que reúna estas condiciones.

7. La reserva de tierras urbanizables necesarias para atender en forma simétrica la demanda de vivienda de interés social y la erradicación de asentamientos precarios

8. El aprovechamiento, conservación y restitución de los recursos naturales, en cuanto afecte a varios municipios y no sea del resorte de la competencia de autoridad ambiental.

9. Los servicios públicos de transporte de pasajeros y de carga cuando su prestación demande el uso de vías terrestres, aéreas o subterráneas que sobrepasen los límites geográficos de uno sólo de los municipios dentro del área.

10. La ordenación y regulación de la movilidad de los habitantes del área metropolitana por vías nacionales, regionales y arteriales que necesariamente deban ser utilizadas por los habitantes del área metropolitana para desplazarse de uno a otro municipio dentro de la misma.

11. El registro y manejo de información geográfica de radio o alcance supramunicipal en el ámbito metropolitano.

12. La atención de hechos exógenos o endógenos al área que generen un acrecentamiento superior en un cincuenta por ciento o más de la tendencia histórica vegetativa de la demanda de un determinado servicio municipal, con un crecimiento asimétrico del gasto público de uno o varios de estos municipios respecto de otro $\mathrm{u}$ otros, superior en un cincuenta por ciento o más respecto de la relación comparativa histórica del gasto aplicado al mismo servicio.

También tendrán el tratamiento de hechos metropolitanos las omisiones absolutas de los municipios del área en la prestación de servicios a su cargo, que generen falta de cobertura en servicios cuyo acceso tenga vocación universal por disposición constitucional.

\section{A manera de síntesis y conclusión}

Nuestro ordenamiento jurídico tomó previsiones legislativas oportunas para dotar a las estructuras urbanas complejas que adquirieron forma en el país en el mediodía del siglo pasado. 
$\mathrm{Su}$ pertinencia, puede ser valorada en abstracto o con énfasis en el arraigo que pueda haber tenido la legislación, no revela signos alentadores.

La coherencia interna de la normativa en cuestión, que en punto de las áreas metropolitanas admite reproche a priori por el hibridismo que profesa en cuanto a los criterios organizacionales empleados, resulta justificada cuando se sigue el trazo de sus causas, enraizadas ellas en la complejidad consustancial del fenómeno metropolitano, que es un hecho de universal aceptación.

Sin embargo, la adhesión preponderante a elementos de tipo corporativista, no consulta la naturaleza misma del fenómeno metropolitano, ni responde satisfactoriamente a la urgente necesidad de adecuación del desarrollo nodal de la economía regional y colombiana para responder a los imperativos de la economía global, y emerge, al lado del uniformismo legislativo en la materia, como uno de los más notables obstáculos para la efectiva organización de la vida metropolitana.

Como todo fenómeno social, la problemática de las áreas metropolitanas, que en este trabajo se enfoca a partir del número de áreas metropolitanas funcionales que aún no se institucionaliza, tanto como a partir del precario arraigo y la reconocida falta de eficacia de las pocas áreas metropolitanas legales existentes, admite ser analizada desde otras perspectivas y, a no dudarlo, la que se observa en este trabajo, puede ser enriquecida y reconstruida con espíritu crítico.

Lo único que no puede aplazarse, es el abandono de la apatía que el asunto despierta en un medio en el que las tendencias se mueven entre un municipalismo nutrido por la influencia de un individualismo extrapolado al ámbito de las organizaciones públicas, y un regionalismo, que además de consultar nuestra realidad variopinta, responde a los requerimientos de la globalización.

Urge la adopción de formas de organización administrativa que consulten la realidad del área metropolitana como fenómeno socio geográfico y que vinculen a sus habitantes con la administración, con la actividad y con el producto del quehacer de esas organizaciones, a través de ejercicios de democracia directa, por manera que estas dejen de ser apreciadas como entidades anodinas, extrañas y sólo reconocibles por el cobro de la contribución de valorización generado por obras de dudosa caracterización metropolitana.

En vano se proyectan los ejercicios de planeación estratégica territorial hacia la configuración de ciudades región, mientras las áreas metropolitanas, nodos como deben ser del desarrollo regional, no se institucionalicen para canalizar y prefigurar pertinentemente el desarrollo de su territorio, ordenar armónicamente los usos del suelo y de los recursos naturales, racionalizar el acceso a los servicios públicos por parte de los habitantes de su territorio, y asegurar la participación equitativa de los diversos presupuestos municipales en la construcción de obra pública articuladora de los núcleos urbanos comprometidos. Ese es el campo de acción que compete al área metropolitana para promover una plataforma económica y social competitiva y sostenible, presupuesto de inserción de la región en escenarios globales de mercado. 
En ese propósito, este trabajo se erige como un aporte más al nutrido debate que requiere la problemática por estos días en que los medios de comunicación anuncian vientos reformistas que harían de Colombia un país metropolitano (El Colombiano, Septiembre 2010).

\section{REFERENCIAS}

Capel, H. (1975). La definición de lo urbano. Estudios Geográficos, No. 138-139 (número especial de "Homenaje al Profesor Manuel de Terán”), febrero-mayo 1975.

Castillo, M. (1999). Reflexiones sobre las Áreas Metropolitanas en Colombia. Pereira.

Ruiz, N. (2008). La migración forzada en Colombia a causa del desplazamiento forzado. Transformación de los hogares y ubicación en el espacio urbano, trabajo presentado en el III Congreso de la Asociación Latinoamericana de Población, realizado en Córdoba, Argentina, del 24 al 26 de setiembre.

Geddes, P. (1915). Cities in Evolution. London: Williams \& Norgate, citado por Brenner Neil en "la formación de la ciudad global y el re-escalamiento del espacio del Estado en la Europa Occidental post-fordista. EURE (Santiago) [online]. 2003, vol.29, n.86 [citado 2010-09-11], pp. 05-35, disponible en: <http://www.scielo.cl/ scielo.php?script $=$ sci_arttext\&pid $=\mathrm{S} 0250-71612003008600001 \& \operatorname{lng}=\mathrm{es} \& \mathrm{nrm}=\mathrm{iso}>$. ISSN 0250-7161. doi: 10.4067/S0250-71612003008600001.

Martínez, C. (2001). Variables de clasificación geográfica según los censos colombianos entre 1964 y 1993, artículo presentado en el Taller col-IPUMS, Homologación de los datos censales de Colombia en Bogotá (Colombia), el 23 y 24 de marzo de 2001. Auspiciado por la Universidad Externado de Colombia y el Minnesota University Population Center.

Barrero, M. (1993). Las áreas metropolitanas. Ed. Civitas, Madrid.

García, Eduardo y Otro. BRC Investor S.A, sociedad calificadora de valores, seguimiento semestral Área Metropolitana del Valle de Aburrá, noviembre de 2007, y primera revisión anual Área Metropolitana de Bucaramanga, noviembre de 2006.

Carrión, G. (2009). Los avatares de la institucionalidad metropolitana en Colombia: una breve revisión a la aplicación de la Ley 128 de 1994. En Desafíos, Bogotá (Colombia), No 20, semestre I.

Moreno, S. Situación actual de las asociaciones de municipios en Colombia. Dirección de Estudios Sectoriales. Contraloría General de la República, noviembre de 2009, consultado en http://www.contraloriagen.gov. co/c/document_library/get file?p_1_id=25611\&folderId=15848373\&name=DLFE-21148.pdf el $15 \overline{\text { de }}$ agosto de 2010.

Naredo, J. (2010). Ciudades y crisis de civilización, en Documentación Social No 119abril- junio 2000, consultado en http://habitat. aq.upm.es/boletin/n15/ajnar.html el 15 de febrero de 2010. 
Varela, C. (1998). La ciudad latinoamericana en nuestros días. En Revista Austral de Ciencias Sociales No 2 19-26.

Safford, Frank y Palacios, Marco. (2005). Colombia, País fragmentado, sociedad dividida, Editorial Norma.

Instituto Geográfico Agustín Codazzi. (2006). Proceso de Urbanización en Colombia. Bogotá 1988, citado en el reporte final de "CONSULTING SERVICES ON DEVELOPMENT OF CITYCASE STUDIES OF THE URBAN SETTLEMENT PATTERN, BOTH FORMAL AND INFORMAL IN THE LAST 20 YEARS IN THE CITIES OF BUCARAMANGA AND CARTAGENA, CEDE - UNIVERSIDAD DE LOS ANDES, Bogotá, abril, pág. 28.

Khoudour-Castéras, David. (2009). Efectos de la migración sobre el trabajo infantil en Colombia, en: Revista de Economía Institucional, Vol. 11, No. 20, primer semestre.

Moncayo, É. (2002). Nuevos enfoques de política regional en América Latina: El caso de Colombia en perspectiva histórica. Las políticas regionales en Colombia. Separata No. 5 de 7, Archivos de Economía, Dirección de Estudios Económicos, Departamento Nacional de Planeación. Bogotá, Julio 5 de 2002.

Ocampo, J.A., Centralismo, descentralización y federalismo en la historia colombiana, (1984), en Crisis Mundial, Protección e Industrialización: Ensayos de Historia Económica Colombiana, Ocampo, J.A., y S. Montenegro, eds., Capítulo 6. DEPARTAMENTO NACIONAL DE ESTADÍSTICA, DANE, Tendencias Demográficas, Censo General 2.005, www.dane.gov.co

Pérez, F. (2003). Estudios Censales, No 13 www.dane.gov.co, Evidencia reciente del comportamiento de la migración interna en Colombia a partir de la Encuesta Continua de Hogares, Bogotá 2.003 www.dane.gov.co

Iregui, A; Melo, L., y Ramírez, M. Productividad Regional y Sectorial en Colombia: Análisis utilizando datos de panel. http://www.google.com.co/ search?rlz=1C1WZPD_enCO382\&sourceid=chrome\&ie $=\mathrm{UTF}-8 \& \mathrm{q}=\mathrm{pdf}$

Maldonado, M. (1999). Ordenamiento jurídico y ordenamiento urbano, en Revista Territorios, julio de 1999, No. 002, Universidad de los Andes, Bogotá.

Gehl, J. (1987) Life Between Buildings, New York: Van Nostrand Reinhold, reimpreso por Arkitektens Forlag, Copenhagen, Denmark, citado por Salíngaros, Nickos en principios de estructura urbana, Design Science Planning, Amsterdam, Holanda, 2005.

Niño, F. (1999). Las migraciones forzadas de población, por la violencia, en Colombia: una historia de éxodos, miedo, terror, y pobreza, en Scripta Nova, revista electrónica de Geografía y Ciencias Sociales de la Universidad de Barcelona No. 45 (33), 1 de agosto.

Boisier, S. (2006). Algunas reflexiones para aproximarse al concepto de ciudad región, - Revista Estudios Sociales, - camara.ccb.org.co.

Friedmann, J. \& G. Wolff (1982). "World city formation: an agenda for research and action". International Journal of Urban and Regional Research, 6: 309-344, 
citado por Luis Mauricio Cuervo, en: Pensar el Territorio: los conceptos de ciudad global y región en sus orígenes y evolución, United Nations Publications, 2003.

Lefevre, C. (2005). Gobernabilidad democrática de las áreas metropolitanas. Experiencias y lecciones internacionales para las ciudades latinoamericanas, en: Gobernar las Metrópolis, BID, Salamanca.

Bermejo, José, Derecho administrativo básico, parte general, Egido Editoral, 2a Ed. Zaragoza, 1998, P. 177).

Brewer- Carias, Allan. Derecho Administrativo. Tomo I. Universidad Externado de Colombia - Universidad Central de Venezuela, Bogotá, 2005, Pp. 388389.

Villegas, J. (El consorcio administrativo en el ámbito local venezolano: aproximación a una descentralización cooperativa. Centro Tachirense de Estudios Municipales, Universidad Católica del Táchira, Revista Provincia No. 8 enero-junio 2002.

Maldonado, A. (2005). El sistema municipal y la superación de la pobreza en Colombia. CEPAL, División de Desarrollo Sostenible y Asentamientos Humanos. Proyecto CEPAL (ROA/28), Pobreza urbana: estrategia orientada a la acción para los gobiernos e instituciones municipales de América Latina y el Caribe, Santiago de Chile, Octubre.

Departamento Nacional de Planeación. Documento creado el 9 de marzo de 2005 en www.dnp.gov.co/PortalWeb/Portals/0/archivos/.../ 1aasociacionmpios.pdf y consulado el 25 de agosto de 2010.

Corte Constitucional. Sentencia C 313 /09.

Martín, R. y Otro. (1986). El área Metropolitana de Alicante: un reto de futuro. Ed. Universidad de Alicante, España.

National Archives and Records Administration. (2000). Federal Register, part IX Office of Managementand budget, Standards for defining Metropolian and micropolitan Statistical areas.

Dureau, F.; C.E. Flórez y M.C. Hoyos. (1993). La movilidad de las poblaciones y su impacto sobre la dinámica del área metropolitana, Documento de trabajo no 1 Bogotá, CEDE-ORSTOM.

Corte Constitucional. C-1096/01, reiterada en C-093/02) (C-1175-01).

Robledo, S. (2008). El panorama territorial colombiano, en: Revista Derecho del Estado No. 21, Universidad Externado de Colombia, Bogotá, Diciembre.

Santamaría, J. (1991). Fundamentos de Derecho Administrativo, Centro de Estudios Ramón Areces, Madrid.

Soja, E. (1971). Postmetrópolis, estudios críticos sobre las ciudades y las regiones. Madrid: Traficantes de Sueños. WHYTE, W.

Henao, J. (1995). $7^{\text {a }}$ Ed. Biblioteca Jurídica Diké. Medellín.

De Lázaro, M.L. y Otros, Universidad Complutense de Madrid, Universidad de León, Universidad San Pablo, - CEU Madrid, 1998. Cervantesvirtual.com. 
Precedo, A. (1988). La red urbana, Madrid.

Dickinson, R. Ciudad, Región y Regionalismo. Una aproximación geográfica a la ecología urbana, 1947, trad. cast. 1961.

Cuadrado, J.; Fernández, J. (2005). El fenómeno metropolitano desde la óptica económica. En Gobernar las Metrópolis, BID, Salamanca.

Gómez, G. (2010). El Colombiano. Medellín, Septiembre.

Giannini, S. (1991). Derecho Administrativo, Serie administración General, Colección Estudios, Ed. Instituto Nacional de Administración Pública, Madrid, $1^{\mathrm{a}}$ ed. Ee Español. 